
and Aromatic Plants

An International Journal

ISSN: 2619-9645 | e-ISSN: 2667-5722

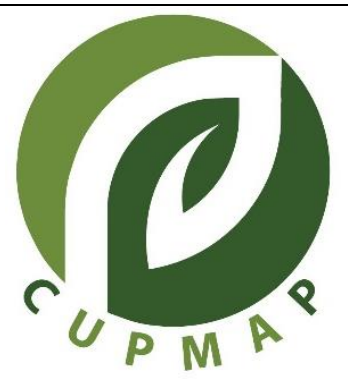

\title{
Effect of the Physalis peruviana and Linum usitatissimum Extracts Against Toluene-Induced Oxidative Damages in Kidney and Liver Tissues of Rats
}

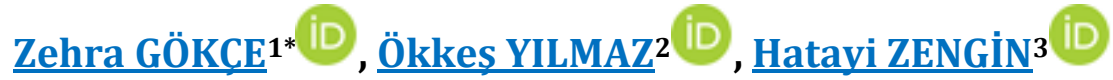 \\ ${ }^{1}$ Kilis 7 Aralık University, Faculty of Health Sciences, Department of Healthcare Management \\ 79000, Kilis, Turkey \\ ${ }^{2}$ Firat University, Faculty of Science, Department of Biology \\ 23119, Elazıg, Turkey \\ ${ }^{3}$ Cumhuriyet University, Faculty of Education, Department of Mathematics and Science Education \\ 58140, Sivas, Turkey \\ *Corresponding author: zhrgkc23@gmail.com
}

https://doi.org/10.38093/cupmap.900518

Received : 21/03/2021 Accepted : 12/05/2021

\section{Abstract}

Toluene causes a great environmental problem, because it is widely used in the industry. This study was intended to examine the effect of golden berry (Physalis peruviana, PP) and flaxseed (Linum usitatissimum, LU) extracts on the malondialdehyde (MDA), reduced glutathione (GSH) fatty acid and lipophilic vitamin content in the kidney and liver tissues of Sprague Dawley male rats, which were oxidative stressed by toluene. PP and LU were extracted and then subjected to vitamin and flavonoid analyses. The rats were divided into four groups as control (C), toluene (T), toluene $+P$. peruviana $(\mathrm{T}+\mathrm{PP})$, and toluene $+L$. usitatissimum $(\mathrm{T}+\mathrm{LU})$. T was injected intraperitoneally at a concentration of $0.3 \mathrm{~mL} / \mathrm{kg}$. In addition, $\mathrm{PP}$ and LU were also injected intraperitoneally at a concentration of $0.5 \mathrm{~mL} / \mathrm{kg}$. The treatments were maintained for two months. Afterwards, the rats were decapitated and tissues were removed. Tissue samples were homogenized using buffer solutions. MDA, GSH, lipophilic vitamin, cholesterol and fatty acid content was also determined. In conclusion, MDA concentration level significantly increased and GSH concentration level significantly decreased in the toluene group $(\mathrm{p}<0.001 ; \mathrm{p}<0.001)$. GSH level increased and the MDA concentration decreased in $\mathrm{T}+\mathrm{PP}$ and $\mathrm{T}+\mathrm{LU}$ treated groups $(\mathrm{p}<0.01 ; \mathrm{p}<0.01)$. Palmitic $(\mathrm{C} 16: 0)$, stearic (C18:0), oleic (C18:n-9), docosahexaenoic (C22:6n-3) and arachidonic (C20:4n-6) acid concentrations were mainly higher in the kidney and liver tissues which were collected from the T+PP and T+LU treated groups than those collected from the control group. The K1, delta-tocopherol and alfa-tocopherol acetate vitamin concentrations were higher in $\mathrm{T}+\mathrm{PP}$ and $\mathrm{T}+\mathrm{LU}$ treated groups than those at group treated with the toxin. Determined concentrations were similar to those measured in the control group. T+PP and T+LU decreased the cholesterol concentration in the kidney and liver tissues $(\mathrm{p}<0.05$ and 0.01 , respectively). According to results; while antioxidant defense systems of toluene groups have decreased, T+PP and T+LU possessed a protective feature against the oxidative stress caused by toluene.

Key Words: Physalis peruviana, Linum usitatissimum, toluene, malondialdehyde, antioxidant, rat

\section{Introduction}

The interest in including herbal products in diet for their health benefits have increased considerably in the recent years (JamshidiKia et al., 2018; Trovato and Ballabio, 2018). Antioxidants of plants origin have high free radical removal and lipid peroxidation 
inhibitor capacities. Most botanical products perform antioxidant activity (Kris-Etherton et al., 2004). Aromatic herbs antioxidants can cure oxidative-induced kidney damage by decreasing lipid peroxidation and increasing the scavenging ability of the antioxidant defense system (Hendawi et al., 2016).

Flaxseed (Linum usitatissimum, LU), a member of the Linaceae family is an important medicinal plant in terms of alpha tocopherol and omega-3 fatty acids. Studies have revealed that flaxseed has anticancer, antiviral, antibacterial, anti-inflammatory and antioxidant properties. LU has also been stated to have a positive effect on heart health due to the intense omega- 3 fatty acid and alpha tocopherol in its composition (Parich et al., 2019; Kaur et al., 2017; Gholaminejhad et al., 2017). Physalis peruviana (PP) is a plant belonging to Physalis genus of the Solanaceae family. PP is used in folk medicine as an antispasmodic, diuretic, antiseptic, sedative and analgesic. PP has been detected exhibit antimicrobial, anti-inflammatory, immunomodulatory and anti-hypercholesterolemic properties (Khalaf-Allah et al.,2016).

The toxicity of many xenobiotics for example, toluene is related to its free radical production. Free radicals are composed of various chemical structures comprising various Reactive Oxygen Species (ROS) containing hydroxyls, superoxides, nitric oxide and lipid peroxides (Arvindkumar, 2011; Arun and Asha, 2007). ROS has a significant impact on the pathogenicity course for many illnesses such as neurodegenerative diseases, cancer, cardiovascular diseases, cataract and rheumatism. Histological analysis of ROS caused by toxic materials points at their effect on the kidney and liver tissue. Liver and kidney are significant organs in all living Mammalia groups the removal of toxins (Aylward et al., 2008; Arvindkumar, 2011). Toluene is an aromatic solvent used in many industrial and commercial practices (AbdelSalam et al., 2020). It is used as a solvent in adhesive, fabric, dye, ink, plastic industries and cleaning products (Bayil et al., 2008). Human beings contact with toluene both as a result of occupational exposure during its commercial production, and its use as a result of bad habits.

In the study, the aims were to determine the effect of PP and LU extracts used to avoid formation of lipid peroxidation (LPO, MDA) resulting in significant damage on cell membrane structure due to oxidative stress caused by toluene, on the MDA and fatty acid composition, lipophilic vitamin content, total cholesterol and several other sterol levels in the kidney and liver tissue of rats. The effect of these extract on the protein and glutathione levels was also investigated in this study.

\section{Material and Methods}

\subsection{Herbal Materials}

Fruits of PP(Physalis peruviana) and seeds of LU (Linum usitatissimum) were used as herbal materials, and they were obtained from herbal shop in Elazig province of Turkey. PP purchased from herbal shop was grown at greenhouses in Antalya and LU was grown in Diyarbakir, Turkey. The fruits of PP and the seeds of LU were extracted with 85\% methanol. Evaporation process for the methanol phase of the extract was performed via the rotatory evaporator equipment under vacuum, and the 
temperature was increased to $55^{\circ} \mathrm{C}$. Afterwards, the dried extracts were dissolved in dimethylsulfoxide (DMSO) and then injected to rats in the groups every other day via intraperitoneal route, and this administration was done throughout 60 days.

\subsection{Flavonoid Analysis of the Extracts via HPLC Device}

The methanolic extracts of the flavonoids were analysed by PREVAIL C18 (15x4.6 mm, $5 \mu \mathrm{m})$ HPLC column tool. Methanol/water/acetonitrile mix (46/46/8, $\mathrm{v} / \mathrm{v} / \mathrm{v}$ ) including $1 \%$ acetic acid was used as the mobile phase ( $\mathrm{Zu}$ et al., 2006). The obtained results were presented as $\mu \mathrm{g} / \mathrm{g}$.

\subsection{Extraction and Analysis of ADEK Vitamins with Phytosterols}

Plant samples were homogenized by mixing n-hexane/isopropyl at $3 / 2(\mathrm{v} / \mathrm{v})$ ratio (Hara and Radin, 1978). And then, the hydrolysis was performed with $5 \% \mathrm{KOH}$ at $85^{\circ} \mathrm{C}$ and the extraction of phytosterols was obtained by adding hexane. The quantity of ADEK vitamins with phytosterols were analyzed at $202 \mathrm{~nm}$ and $326 \mathrm{~nm}$ by a UV detector on HPLC equipment (Katsanidis and Addis, 1999).

\subsection{Experimental Animals}

Spraque Dawley male rats used in experimental research were obtained from the Experimental Research Center at School of Medicine, Firat University (22.05.2012/66). The experimental processes were performed at the same institute. Four groups were formed with the rats. Substance concentrations intraperitoneally for these groups were as noted below:
1.C $(\mathrm{n}=7): 0.3 \mathrm{~mL} / \mathrm{kg}$ at olive oil

2.T ( $\mathrm{n}=7$ ): a mix of $0.3 \mathrm{~mL} / \mathrm{kg}$ of $20 \% \mathrm{~T}$ with olive oil $3 . \mathrm{T}+\mathrm{PP}(\mathrm{n}=7): 0.3 \mathrm{~mL} / \mathrm{kg}$ of $\mathrm{T}+0.5 \mathrm{~mL} / \mathrm{kg}$ of extract $\mathrm{PP}$ $4 . \mathrm{T}+\mathrm{LU}(\mathrm{n}=7): 0.3 \mathrm{~mL} / \mathrm{kg}$ of $\mathrm{T}+0.5 \mathrm{~mL} / \mathrm{kg}$ of extract $\mathrm{LU}$

As far as ethical committee approved, the specimens anaesthetized to sacrifice by withdrawing blood from the animal body, and after animals were decapitated. Shortly after this process, kidney and liver tissue samples were divided. These samples were shortly cleaned with $0.9 \%$ serum physiologic, and they were stored at $-80^{\circ} \mathrm{C}$ in order to use biochemical analyses.

\subsection{ADEK and Cholesterol Levels Determination via HPLC Device}

Firstly, $5 \mathrm{~mL}$ of supernatant and $5 \% \mathrm{KOH}$ solution were put in 25-mL test tubes with caps. After that the tubes were vortexed, they were incubated at $85^{\circ} \mathrm{C}$ for 15 minutes. Later, the tubes were taken from incubator and, $5 \mathrm{~mL}$ of distilled water was added and mixed. Evaporation of the hexane phase was performed by nitrogen stream in order to obtain dried extract. Then, this extract was dissolved in $1 \mathrm{~mL}$ of acetonitrile/ methanol $(50 \%+50 \%, v / v)$ mix. They were placed into the vials in order to analyze ADEK vitamins (Katsanidis and Addis, 1999). The analyses were done on Shimadzu fully equipment HPLC equipment. Computations were performed by Class VP 6.27 program (Shimadzu, Kyoto Japan).

\subsection{Total Protein Levels and GSH Determination}

In order to investigate the glutathione and total protein levels in the tissues, 28 different samples collected from the specimens were homogenized in $0.1 \mathrm{~m}$ TrisHCl and $20 \mathrm{mM}$ EDTA (pH:7) buffer, later divided into tissue pellet by centrifugation at $9000 \mathrm{rpm}$ for $5 \mathrm{~min}$ at 
$+4^{\circ} \mathrm{C}$. After this process, the supernatant was separated from two aliquots, one of which was used for GSH test. Therefore, the proteins at supernatant were precipitated by using $1 \mathrm{ml}$ of $5 \%$ metaphosphoric acid reactive. This mix was centrifuged at 4500 rpm to $4 \mathrm{~min}$, thus the pellet was settled and the supernatant was removed into another tube. The supernatant was suplementated 1 $\mathrm{mL} 150 \mu \mathrm{l}$ DTNB with $2 \mathrm{~mL}$ of $0.3 \mathrm{M}$ Na2HPO4 solution, the color altered to yellow was read at $412 \mathrm{~nm}$ against blank (Teare et al., 1993). The total protein analyzes were carried out with the supernatant obtained from the glutathione analyzes. Then, $50 \mu \mathrm{l}$ the supernatant was separated with subjected to Lowry (1951) method.

\subsection{HPLC Analyzes of the Quantity of LPO}

One ml sample was obtained from animal group; $0.6 \%$ 2-thiobarbituric acid (TBA) chemical materials and $2 \mathrm{ml}$ distilled water was put into the mixture. Later, the mixed samples were kept at $90^{\circ} \mathrm{C}$ for 60 minutes. Then, $3 \mathrm{ml}$ butanol was included into the samples and consequently the pink color formed after the chemical reaction. The samples were centrifuged and the intensity of the supernatant section was kept into the vials.

LPO measurements were performed via a fluorescence detector on the HPLC tool, which is Inertsil ODS-3 C18 HPLC column (150x4.6 $\mu \mathrm{m})$. The mobile phase was formed using 75\% ACN / $30 \mathrm{mM} \mathrm{KH2PO4}$ $(\mathrm{pH}=5)$ mixture. 5 minutes was determined as analyzes time. As a standard of LPO, 1,1,3,3-tetraethoxypropane (TEP) was utilized (Ohkawa et al., 1979). The analysis results were given with $\mathrm{nmol} / \mu \mathrm{l}$.

\subsection{Isolation of Fatty Acids by Gas Chromatography}

Fatty acids were isolated by adding $10 \mathrm{ml}$ $3 / 2$ (v/v) hexane / isopropanol mixture (Hara and Radin, 1978) on liquid phase of the samples remaining after LPO. Then, hexane phase was placed into different test tubes and $5 \mathrm{ml} 2 \%$ methanolic sulfuric acid was added into the tube. Then, the mixture was kept in the incubator at $55^{\circ} \mathrm{C}$ to 12 hours. Hence, $5 \mathrm{ml}$ of $5 \%$ sodium chloride was added into tube and then the fatty acid methyl esters were extracted to $5 \mathrm{ml}$ of hexane. Furthermore, $5 \mathrm{ml}$ of $2 \%$ KHCO3 solution was placed into the mixture, and the hexane phase was evaporated by nitrogen stream (Christie, 1990). Finally, fatty acid methyl ester residues were dissolved in $1 \mathrm{ml}$ heptane and placed into vials. Fatty acid methyl ester was determined by Shimadzu GC 17 device equipment (Kyoto, Japan).

\subsection{Data Analyses}

SPSS 15.0 Software was utilized to analyze results. The control and experimental groups was compared with the analyzes of ANOVA method with LSD tests. The obtained data were reported as mean \pm SEM. The difference between the groups, $\mathrm{p}>0.05$, $\mathrm{p}<0.05, \mathrm{p}<0.01$, and $\mathrm{p}<0.001$ values were used to determine meaning of the data.

\section{Results and Discussion}

The reduced GSH, total protein with MDA concentrations determined at kidney tissue were displayed in Table 1 . The GSH concentration in the kidney tissue in group $\mathrm{T}$ was greatly less than that of the control group $(\mathrm{p}<0.001)$. The GSH concentration was statistically higher in groups $\mathrm{T}+\mathrm{LU}$ and $\mathrm{T}+\mathrm{PP}$ than that of the control group $(\mathrm{p}<0.01)$. Total protein content of the kidney tissue in groups $\mathrm{T}, \mathrm{T}+\mathrm{PP}$ and $\mathrm{T}+\mathrm{LU}$ were all 
partially statistically higher than that in the control group $(\mathrm{p}<0.05)$. After all, there was no noticeable change among toluene treated groups ( $p>0.05)$.

Table 1. GSH, Total protein, MDA concentrations at kidney tissue of the rats*

\begin{tabular}{lccc}
\hline Groups & GSH $(\boldsymbol{\mu m o l} / \mathbf{g})$ & Total Protein $(\mathbf{m g} / \mathbf{g})$ & MDA $(\mathbf{n m o l} / \mathbf{g})$ \\
\hline $\mathbf{C}$ & $2.19 \pm 0.11$ & $146.13 \pm 2.54$ & $29.00 \pm 1.18$ \\
$\mathbf{T}$ & $1.13 \pm 0.5^{\mathrm{d}}$ & $126.26 \pm 1.76^{\mathrm{b}}$ & $45.40 \pm 0.81^{\mathrm{d}}$ \\
$\mathbf{T}+\mathbf{L U}$ & $2.73 \pm 0.13^{\mathrm{c}}$ & $123.52 \pm 2.88^{\mathrm{b}}$ & $37.31 \pm 1.48^{\mathrm{c}}$ \\
$\mathbf{T}+\mathbf{P P}$ & $2.50 \pm 0.21^{\mathrm{c}}$ & $122.73 \pm 2.83^{\mathrm{b}}$ & $39.62 \pm 1.00^{\mathrm{c}}$ \\
\hline
\end{tabular}

*Each value is the mean \pm S.E. (standard error) of 7 repetitions. Superscripts after values in a same line with different letters represent significant difference. a: $p>0.05, b: p<0.05$, c: $p<0.01, d: p<0.001$.

a: Values of $p>0.05$ is not statistically significant.

b: Values of $\mathrm{p}<0.05$ is statistically significant.

c: Values of $\mathrm{p}<0.01$ is statistically more significant

$\mathrm{d}$ : Values of $\mathrm{p}<0.001$ is statistically most significant

C: Control, T: Toluene, LU: Linum usitatissimum, PP: Pysalis peruviana, T+LU: Toluene+ Linum usitatissimum, , T+PP: Toluene+ Physalis peruviana GSH: Reduced glutathione, MDA: Malondialdehyde.

The reduced GSH, total protein with MDA concentrations determined at liver tissue were presented in Table 2. The GSH concentration at liver tissue in group $\mathrm{T}$ was much lower than control group $(\mathrm{p}<0,001)$. Besides, GSH concentration in the T+PP and $\mathrm{T}+\mathrm{LU}$ groups was lower than the control group $(\mathrm{p}<0.01)$. The amount of MDA concentration was present in the $T$ groups while it was not found at control group $(\mathrm{p}<0.001)$. This concentration was found at $\mathrm{T}+\mathrm{LU}$ group, and it was also significantly high at $\mathrm{T}+\mathrm{PP}$ group $(\mathrm{p}<0.01 ; \mathrm{p}<0.01$.

Table 2. GSH, Total protein, MDA concentrations at liver tissue of the rats*

\begin{tabular}{lccc}
\hline Groups & GSH $(\boldsymbol{\mu m o l} / \mathbf{g})$ & Total Protein $\mathbf{( m g / g )}$ & MDA $(\mathbf{n m o l} / \mathbf{g})$ \\
\hline $\mathbf{C}$ & $8.05 \pm 4.08$ & $180.71 \pm 13.54$ & $42.39 \pm 2.72$ \\
$\mathbf{T}$ & $1.91 \pm 0.04^{\mathrm{d}}$ & $171.40 \pm 8.72^{\mathrm{b}}$ & $50.94 \pm 2.25^{\mathrm{c}}$ \\
$\mathbf{T}+\mathbf{L U}$ & $4.17 \pm 0.21^{\mathrm{c}}$ & $197.24 \pm 17.98^{\mathrm{b}}$ & $45.21 \pm 4.61^{\mathrm{b}}$ \\
$\mathbf{T + P P}$ & $4.27 \pm 0.21^{\mathrm{c}}$ & $194.81 \pm 12.80^{\mathrm{b}}$ & $43.68 \pm 2.02$ \\
\hline
\end{tabular}

*The meaning of the symbols is given under Table 1.

The analyses that were performed using the HPLC device showed the methanol extract of PP and LU (Tables 3,4). When analyzed in terms of LU lipophilic vitamins and phytosterols $\alpha$-tokoferol, stigmasterol, ergosterol high amounts were determined as 70.92, 34.7 and 21.85, respectively. In the analysis lipophilic vitamins and phytosterols of PP $\alpha$-tokoferol, stigmasterol, ergosterol high amounts were determined as 85.29, 38,10 and 21,54 respectively.
Table 3. Flavonoid contents of herbal materials in methanolic extracts $(\mu \mathrm{g} / 0.6 \mathrm{~g})$.

\begin{tabular}{lcc}
\hline Flavonoids & PP & LU \\
\hline Cathechin & 2.33 & 3.26 \\
Rutin & 1.27 & 2.86 \\
Resveratrol & 0.02 & 0.01 \\
Myricetin & 0.26 & 0.20 \\
Morin & 0.05 & 0.02 \\
Naringenin & 0.02 & 0.01 \\
Quercetin & 0.01 & 0.01 \\
\hline
\end{tabular}

*LU: Linum usitatissimum, PP: Pysalis peruviana 
High amounts of catechin, rutin and myricetin were detected in PP and LU in terms of flavonoid content.

Table 4. Lipofilik vitamin and phytosterol of herbal materials in methanolic extracts $(\mu \mathrm{g} / 0.6 \mathrm{~g})^{*}$

\begin{tabular}{lcc}
\hline $\begin{array}{l}\text { Lipophilic Vitamin } \\
\text { and Phytosterol }\end{array}$ & PP & LU \\
\hline $\mathbf{K}_{\mathbf{1}}$ & 3.63 & 4.06 \\
$\mathbf{K}_{\mathbf{2}}$ & 2.92 & 3.54 \\
$\boldsymbol{\alpha}$-Tokoferol & 70.92 & 85.29 \\
R-Tokoferol & 18.33 & 14.96 \\
$\mathbf{D}_{\mathbf{3}}$ & 1.05 & 1.14 \\
Retinol & 0.06 & 0.02 \\
Ergosterol & 21.85 & 21.54 \\
Stigmasterol & 34.77 & 38.10 \\
$\boldsymbol{\beta}$-sitosterol & 20.88 & 22.34 \\
\hline *U: Linum usitatissimum, PP: Pysalis peruviana
\end{tabular}

D2 concentration was very significantly lower in group $\mathrm{T}$ by comparison with the control group $(\mathrm{p}<0.001) . \quad \delta$ tocopherol concentration was partially higher in groups $\mathrm{T}+\mathrm{PP}$ and $\mathrm{T}+\mathrm{LU}$ in comparison to that of control group $(p<0.05)$ with the $\alpha$ tocopherol acetate concentration was importantly higher with at groups $\mathrm{T}+\mathrm{PP}$ and $\mathrm{T}+\mathrm{LU}$ by comparison with the control group $(p<0.01)$. The retinol concentration was importantly higher at group $\mathrm{T}+\mathrm{PP}$ in comparison with the control group $(\mathrm{p}<0.01)$. Retinol acetate concentration at $\mathrm{T}$ group was very importantly lower than that of the control group $(p<0.001)$, with the value of at group $\mathrm{T}+\mathrm{PP}$ was not importantly vary from the control group ( $p>0.05)$. The cholesterol level in group $\mathrm{T}$ was partially higher than that of the control group $(\mathrm{p}<0.05)$ (Table 5).

A comparison of the ADEK vitamin and cholesterol content in the liver tissue of the $\mathrm{T}$, $\mathrm{T}+\mathrm{LU}$ and $\mathrm{T}+\mathrm{PP}$ groups with the control group designated that the vitamin $\mathrm{K} 1$ concentration at $\mathrm{T}$ and $\mathrm{T}+\mathrm{PP}$ groups $(\mathrm{p}<0.01)$.The vitamin $\mathrm{K} 2$ was not significantly the $\mathrm{T}+\mathrm{PP}$ groups whereas $\mathrm{K} 2$ was significantly lower the $\mathrm{T}$ groups relatively to that of the control group $(\mathrm{p}<0.01)$.

Table 5. Lipophilic vitamins and cholesterol concentrations in the kidney tissue of rats*

\begin{tabular}{lcccc}
\hline Parameters & $\mathbf{C}$ & $\mathbf{T}$ & $\mathbf{T}+\mathbf{P P}$ & $\mathbf{T}+\mathbf{L U}$ \\
\hline Vitamin $\mathbf{K}_{\mathbf{1}} \boldsymbol{\mu g} / \mathbf{g}$ tissue & $1.72 \pm 0.13$ & $1.58 \pm 0.07$ & $2.20 \pm 0.12^{\mathrm{b}}$ & $2.07 \pm 0.12^{\mathrm{b}}$ \\
Vitamin $\mathbf{K}_{\mathbf{2}} \boldsymbol{\mu g} / \mathbf{g}$ tissue & $4.23 \pm 0.20$ & $3.79 \pm 0.18$ & $5.75 \pm 0.26^{\mathrm{b}}$ & $4.56 \pm 0.14$ \\
Vitamin $\mathbf{D}_{\mathbf{2}} \boldsymbol{\mu g} / \mathbf{g}$ tissue & $1.50 \pm 0.11$ & $0.33 \pm 0.13^{\mathrm{d}}$ & $0.61 \pm 0.171$ & $0.84 \pm 0.44$ \\
Vitamin $_{\mathbf{3}} \boldsymbol{\mu \mathrm { g }} / \mathbf{g}$ tissue & $1.30 \pm 0.16$ & $1.48 \pm 0.85$ & $1.89 \pm 0.10^{\mathrm{b}}$ & $1.54 \pm 0.76$ \\
$\boldsymbol{\delta}$-Tocopherol $\boldsymbol{\mu g} / \mathbf{g}$ tissue & $1.44 \pm 0.10$ & $1.06 \pm 0.08$ & $1.85 \pm 0.11^{\mathrm{b}}$ & $1.71 \pm 0.16^{\mathrm{b}}$ \\
$\boldsymbol{\alpha}$-Tocopherol $\boldsymbol{\mu g} / \mathbf{g}$ issue & $16.22 \pm 0.52$ & $13.39 \pm 0.30$ & $13.09 \pm 0.23$ & $15.21 \pm 0.50$ \\
$\boldsymbol{\alpha}$-Tocopherol acetate $\boldsymbol{\mu g} / \mathbf{g}$ tissue & $7.49 \pm 0.21$ & $5.77 \pm 0.20$ & $9.06 \pm 0.20^{\mathrm{c}}$ & $7.76 \pm 0.13^{\mathrm{b}}$ \\
Retinol $\boldsymbol{\mu g} / \mathbf{g}$ tissue & $3.77 \pm 0.16$ & $2.12 \pm 0.17$ & $4.58 \pm 0.23^{\mathrm{c}}$ & $3.64 \pm 0.19$ \\
Cholesterol $\boldsymbol{\mu m o l} / \mathbf{g}$ tissue & $3.78 \pm 0.15$ & $4.42 \pm 0.15^{\mathrm{b}}$ & $3.18 \pm 0.15$ & $3.47 \pm 0.20$
\end{tabular}

*The meaning of the symbols is given under Table 1.

$\mathrm{D}_{2}$ concentration was importantly lower the $\mathrm{T}$ group in comparison to that of the control group ( $\mathrm{p}>0.05)$. Vitamin $\mathrm{D}_{3}$ concentration at $\mathrm{T}+\mathrm{PP}$ groups was not importantly varied from the control group $(\mathrm{p}>0.05) . \quad \delta$ tocopherol concentration was significantly higher in groups $\mathrm{T}$ with $\mathrm{T}+\mathrm{PP}$ while it was importantly lower as regards the control group $(p<0.01)$ and $(p<0.001)$. Alpha tocopherol concentration was partially remained group by with to the control group whereas the values of $\mathrm{T}+\mathrm{LU}$ with $\mathrm{T}$ groups were significantly lower $(p>0.05)(p<0.01)$ and $(\mathrm{p}<0.001)$. Retinol concentration in $\mathrm{T}$ with $\mathrm{T}+\mathrm{LU}$ groups was not important difference determined $(\mathrm{p}<0.05)$ and ( $>>0.05)$, (Table 6). 
The C16:0 (palmitic acid) concentration was importantly lower at the $\mathrm{T}$ group in comparison to the control group $(p<0.01)$ and was partially higher at $\mathrm{T}+\mathrm{PP}$ group $(\mathrm{p}<0.05)$. The C16:1 (palmiteolic acid) concentration was importantly lower at $\mathrm{T}$ group in comparison to control group $(\mathrm{p}<0.01)$. The C18:0 (stearic acid) concentration was partially higher at $\mathrm{T}+\mathrm{PP}$ group in comparison to the control group $(\mathrm{p}<0.05)$. The C16:0 (palmitic acid) concentration was importantly lower at the $\mathrm{T}$ group in comparison to the control group $(\mathrm{p}<0.01)$ and was partially higher at $\mathrm{T}+\mathrm{PP}$ group ( $\mathrm{p}<0.05)$. The $\mathrm{C} 16: 1$ (palmiteolic acid) concentration was importantly lower at $\mathrm{T}$ group in comparison to control group $(\mathrm{p}<0.01)$.

Table 6. Lipophilic vitamins and cholesterol concentrations in the liver tissue of the rats*

\begin{tabular}{|c|c|c|c|c|}
\hline Parameters & $\mathbf{C}$ & $\mathbf{T}$ & T+PP & $T+L U$ \\
\hline Vitamin $K_{1} \mu \mathrm{g} / \mathrm{g}$ tissue & $6.79 \pm 0.66$ & $2.41 \pm 1.05^{c}$ & $5.47 \pm 0.23^{b}$ & $9.06 \pm 1.46^{c}$ \\
\hline Vitamin $K_{2} \mu \mathrm{g} / \mathrm{g}$ tissue & $4.39 \pm 0.38$ & $2.31 \pm 0.26^{c}$ & $3.86 \pm 0.22$ & $4.36 \pm 0.25^{\mathrm{a}}$ \\
\hline Vitamin $D_{2} \mu \mathrm{g} / g$ tissue & $3.61 \pm 0.18$ & $1.59 \pm 1.87 \mathrm{c}$ & $2.56 \pm 0.11$ & $2.45 \pm 0.62$ \\
\hline Vitamin $D_{3} \mu \mathrm{g} / \mathrm{g}$ tissue & $2.44 \pm 0.59$ & $1.73 \pm 0.59$ & $3.33 \pm 0.16$ & $2.93 \pm 0.74^{a}$ \\
\hline$\delta$-Tocopherol $\mu g / g$ tissue & $2.23 \pm 0.55$ & $0.94 \pm 0.21^{\mathrm{d}}$ & $2.55 \pm 0.26$ & $4.21 \pm 0.50^{c}$ \\
\hline$\alpha$-Tocopherol $\mu \mathrm{g} / \mathrm{g}$ tissue & $9.63 \pm 1.42$ & $3.21 \pm 1.00^{\mathrm{d}}$ & $7.21 \pm 0.56^{c}$ & $10.19 \pm 1.07^{b}$ \\
\hline$\alpha$-Tocopherol acetate $\mu \mathrm{g} / \mathrm{g}$ tissue & $8.46 \pm 0.21$ & $5.77 \pm 0.20$ & $9.72 \pm 0.20^{c}$ & $7.76 \pm 0.13^{b}$ \\
\hline Retinol $\mu \mathrm{g} / \mathrm{g}$ tissue & $342.05 \pm 22.6$ & $310.01 \pm 11.7^{b}$ & $329.55 \pm 19.2^{b}$ & $342.41 \pm 11.6^{\mathrm{a}}$ \\
\hline Cholesterol $\mu \mathrm{mol} / \mathrm{g}$ tissue & $2.90 \pm 0.41$ & $3.62 \pm 0.18^{\mathrm{b}}$ & $2.53 \pm 0.16$ & $2.61 \pm 0.58$ \\
\hline
\end{tabular}

*The meaning of the symbols is given under Table 1 .

Table 7. Fatty acid concentrations in the kidney tissue of the rats $(\mathrm{mg} / \mathrm{g})^{*}$

\begin{tabular}{|c|c|c|c|c|}
\hline Fatty acids & C & $\mathbf{T}$ & $\mathbf{T}+\mathbf{P P}$ & $T+L U$ \\
\hline C16:0 & $2.51 \pm 0.04$ & $1.65 \pm 0.01^{c}$ & $2.08 \pm 0.04$ & $2.81 \pm 0.03^{b}$ \\
\hline C16:1 & $0.39 \pm 0.01$ & $0.19 \pm 0.01^{c}$ & $0.25 \pm 0.01$ & $0.30 \pm 0.01$ \\
\hline C18:0 & $1.93 \pm 0.04$ & $1.69 \pm 0.04$ & $1.71 \pm 0.06$ & $2.34 \pm 0.06^{\mathrm{b}}$ \\
\hline C18:1n-9 & $1.01 \pm 0.08$ & $0.93 \pm 0.02^{\mathrm{a}}$ & $0.91 \pm 0.03^{a}$ & $1.33 \pm 0.02^{\mathrm{b}}$ \\
\hline C18:1n-7 & $0.40 \pm 0.01$ & $0.27 \pm 0.01$ & $0.33 \pm 0.01$ & $0.48 \pm 0.01^{b}$ \\
\hline C18:2n-6t & $0.07 \pm 0.01$ & $0.03 \pm 0.01$ & $0.05 \pm 0.01$ & $0.08 \pm 0.01^{\mathrm{a}}$ \\
\hline C18:2n-6c & $2.02 \pm 0.07$ & $1.29 \pm 0.05^{c}$ & $1.64 \pm 0.04^{b}$ & $2.20 \pm 0.06^{\mathrm{b}}$ \\
\hline$C 20: 3 n-6$ & $0.10 \pm 0.01$ & $0.08 \pm 0.01$ & $0.10 \pm 0.01^{\mathrm{a}}$ & $0.12 \pm 0.01$ \\
\hline C20:4n-6 & $3.77 \pm 0.11$ & $3.15 \pm 0.07$ & $3.47 \pm 0.06$ & $4.33 \pm 0.04 b$ \\
\hline$C 22: 6 n-3$ & $0.16 \pm 0.01$ & $0.14 \pm 0.01$ & $0.16 \pm 0.01^{\mathrm{a}}$ & $0.20 \pm 0.01^{b}$ \\
\hline Others & $0.78 \pm 0.03$ & $0.52 \pm 0.03$ & $0.53 \pm 0.01$ & $0.75 \pm 0.01^{\mathrm{a}}$ \\
\hline$\Sigma S F A$ & $4.44 \pm 0.03$ & $3.34 \pm 0.05^{c}$ & $3.79 \pm 0.10$ & $5.15 \pm 0.09 c$ \\
\hline IMUFA & $1.80 \pm 0.10$ & $1.39 \pm 0.04^{c}$ & $1.49 \pm 0.05$ & $2.11 \pm 0.04^{b}$ \\
\hline 乏PUFA & $6.12 \pm 0.21$ & $4.69 \pm 0.14^{c}$ & $5.42 \pm 0.12$ & $6.93 \pm 0.13^{c}$ \\
\hline 乏Fatty Acid & $13.14 \pm 0.37$ & $9.94 \pm 0.27 c$ & $11.23 \pm 0.29$ & $14.94 \pm 0.2^{b}$ \\
\hline
\end{tabular}

*The meaning of the symbols is given under Table 1 .

$\Sigma$ : Total.

¿SFA: Total Saturated Fatty Acid.

IMUFA: Total Monounsaturated Fatty Acid.

SPUFA: Total Polyunsaturated Fatty Acid.

The C18:0 (stearic acid) concentration was partially higher at $\mathrm{T}+\mathrm{PP}$ group in comparison to the control group $(\mathrm{p}<0.05)$.
C18:1n9 (oleic acid) concentration of the T and $\mathrm{T}+\mathrm{LU}$ groups was similar to that of the control group $(p>0.05)$, and the 
concentration at $\mathrm{T}+\mathrm{PP}$ group was partially higher $(p<0.05)$. The C18:1n7 (Vaccenic acid) concentration was partially higher at $\mathrm{T}+\mathrm{PP}$ group in comparison to the control group $(\mathrm{p}<0.05)$ whereas the C18:2n6t (linoleic acid) concentration was statistically like to that of the control group (Table 7). C20:3n6 (dihomo - gamma linoleic acid) concentration of the T+LU group was similar to that of the control group ( $>>0.05)$ whereas C20:4n6 (arachidonic acid) concentration was significantly increased in the $\mathrm{T}+\mathrm{PP}$ group in comparing to that in the control group $(p<0.05) . \quad$ C22:6n3 (docosohexoeonic acid) concentration partially increased in the $\mathrm{T}+\mathrm{PP}$ group in comparing to the control group $(\mathrm{p}<0.05)$ whereas the gradient at concentrations between that at $\mathrm{T}+\mathrm{LU}$ group with the control group was determined as insignificant ( $>0.05$ ) (Table 7). A comparison of the $\mathrm{T}$, $\mathrm{T}+\mathrm{LU}$ and $\mathrm{T}+\mathrm{PP}$ groups with the control group indicated that the $\Sigma$ SFA (saturated fatty acid) and SPUFA (total unsaturated fatty acid) concentration was significantly lower within group $\mathrm{T}$ with higher in $\mathrm{T}+\mathrm{PP}$ $(\mathrm{p}<0.01)$. The SMUFA (total mono unsaturated fatty acid) and total fatty acid concentration was significantly lower in group $\mathrm{T}(\mathrm{p}<0.01)$ and partially higher in $\mathrm{T}+\mathrm{PP}(\mathrm{p}<0.05)$ (Table 7).

A comparison of the fatty acid content in liver tissue C16:0, C18:0, C18:2n6c and other fatty acid were significantly lower $\mathrm{T}$ group in comparison to the mean value of the control group $(\mathrm{p}<0.001)$. The $\mathrm{C} 18: 1 \mathrm{n} 9$ concentration was significantly lower in $\mathrm{T}$ with $\mathrm{T}+\mathrm{LU}$ groups $(\mathrm{p}<0.001)$. C18:1n7 concentration in the $\mathrm{T}+\mathrm{PP}$ groups was not statistically similar to that of the control group ( $\mathrm{p}>0.05)$. In addition, C20:4n6 concentration was determined to be significantly different in the $\mathrm{T}+\mathrm{LU}$ and $\mathrm{T}+\mathrm{PP}$ groups from the values of the control group ( $>0.05)$, (Table 8).

Table 8. Fatty acid concentrations in the liver tissue of the rats $(\mathrm{mg} / \mathrm{g})$ *

\begin{tabular}{|c|c|c|c|c|}
\hline Fatty acids & $\mathrm{C}$ & $\mathbf{T}$ & $T+L U$ & $\mathrm{~T}+\mathrm{PP}$ \\
\hline C16:0 & $1.69 \pm 0.17$ & $1.00 \pm 0.15^{c}$ & $1.21 \pm 0.02$ & $1.11 \pm 0.14$ \\
\hline C16:1 & $0.21 \pm 0.01$ & $0.11 \pm 0.01$ & $0.12 \pm 0.01$ & $0.13 \pm 0.01$ \\
\hline C18:0 & $2.56 \pm 1.53$ & $1.05 \pm 0.19 c$ & $1.21 \pm 0.02$ & $1.28 \pm 0.17$ \\
\hline C18:1n-9 & $0.69 \pm 0.04$ & $0.19 \pm 0.08^{c}$ & $0.16 \pm 0.01^{c}$ & $0.25 \pm 0.03$ \\
\hline C18:1n-7 & $0.21 \pm 0.03$ & $0.10 \pm 0.04$ & $0.12 \pm 0.01$ & $0.21 \pm 0.03^{a}$ \\
\hline C18:2n-6t & $1.44 \pm 0.20$ & $0.90 \pm 0.20^{c}$ & $1.19 \pm 0.06$ & $1.01 \pm 0.09$ \\
\hline C18:2n-6c & $0.09 \pm 0.01$ & $0.07 \pm 0.01$ & $0.08 \pm 0.01^{\mathrm{a}}$ & $0.08 \pm 0.01^{\mathrm{a}}$ \\
\hline C20:3n-6 & $0.18 \pm 0.07$ & $0.02 \pm 0.01^{d}$ & $0.03 \pm 0.01^{d}$ & $0.09 \pm 0.01$ \\
\hline$C 20: 4 n-6$ & $2.45 \pm 0.47$ & $2.14 \pm 0.36$ & $2.42 \pm 0.09^{a}$ & $2.36 \pm 0.01^{\mathrm{a}}$ \\
\hline$C 22: 6 n-3$ & $0.90 \pm 0.10$ & $0.49 \pm 0.14$ & $0.69 \pm 0.04$ & $0.50 \pm 0.08$ \\
\hline Others & $0.63 \pm 0.30$ & $0.23 \pm 0.05^{c}$ & $0.40 \pm 0.02$ & $0.32 \pm 0.05$ \\
\hline ESFA & $4.25 \pm 1.70$ & $2.05 \pm 0.34^{c}$ & $2.42 \pm 0.04$ & $2.39 \pm 0.31$ \\
\hline इMUFA & $1.11 \pm 0.08$ & $0.40 \pm 0.13^{c}$ & $0.40 \pm 0.03^{c}$ & $0.59 \pm 0.07$ \\
\hline 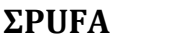 & $4.97 \pm 0.84$ & $3.55 \pm 0.71^{\mathrm{c}}$ & $4.33 \pm 0.20$ & $3.96 \pm 0.19$ \\
\hline $\begin{array}{l}\Sigma \text { Fatty } \\
\text { Acid }\end{array}$ & $10.33 \pm 2.92$ & $6.23 \pm 1.23^{c}$ & $7.55 \pm 0.29$ & $7.26 \pm 0.62$ \\
\hline
\end{tabular}

*The meaning of the symbols is given under Table 1.

$\Sigma$ : Total.

¿SFA: Total Saturated Fatty Acid.

IMUFA: Total Monounsaturated Fatty Acid.

IPUFA: Total Polyunsaturated Fatty Acid. 
Discussion: The biological observation of exposure to toxic chemicals in work environment is important for evaluating the risks that threaten human health and the provision of occupational safety (Gerin et al., 1998; EPA, 1959). Toluene and its metabolites cause damage in many different types of tissue through oxidative stress (Gotohda et al., 2009). During the toxicity research of toluene, many rats died due to nephrosis which was common among them. Also, there was damage to the tubular epithelia of the kidney because of a terminal disease in rats. The researchers examined the rats' kidneys by taking parts to determine any sign of hyaline droplets to proximal tubules. The findings were negative. In addition, there were histopathologic lesions in liver which consisted of hepatocellular hypertrophy (Huff , 2003; Hendawi et al., 2016). The genotoxic outcome of such DNA oxidation acts a part of the pathogenesis of several illnesses Costa et al., (2005) as well as the emergence of cancer and neurodegenerative disorders (Kayhan et al., 2009).

Our results indicated that the MDA concentration in the kidney tissue of the rats that were treated with toluene was significantly high, but MDA concentration was the highest in the liver tissue (Table 1), since toluene that is absorbed by the blood is diffused through the living Mammalia groups. The increase in MDA concentration is generally accepted to be a predictive factor of the lipid peroxidation initiating as a result of the oxidative stress, which was, in this case, caused by toluene. The toxic effects of toluene as indicated by high MDA levels are associated with free radicals, and ROS encountered in house painters, who were exposed to toluene, causes damage in the biological membranes (Kris-Etherton et al., 2004). A study conducted by Moro compared the blood samples of male workers from several industrial sectors, who were exposed to low concentrations of toluene, with that of males who were not associated with any type of occupation. The blood MDA level of the industrial workers was reported to be twice more than the level found in non-workers [Moro et al., 2010].House painters, who are exposed to low concentrations of toluene constantly, were determined to be affected more from oxidative damage (Moro et al., 2012). This study indicated that the increase in the MDA concentration of the group treated with $P$. peruviana extract together with toluene was relatively lower than that of the group treated with the chemical alone. A comparison of the results of the experiments conducted with the control group and the toluene-treated group indicated that the MDA concentration was considerably higher in the group $\mathrm{T}$ whereas this level was limited in groups supplemented with the extract (Table 1). Moreover, ROS production increase leads oxidative stress induced kidney damage. Oxidative stress induced kidney damage is significantly reduced by antioxidants (Nasri, 2013).

Several plant species and their oil extracts and phytochemicals have widely been used as antioxidants in the therapeutics and prevention of several diseases in traditional medicine (Scalzo et al., 2005). Therefore, the researchers of this study also investigated the effect of $P$. peruviana and flaxseed extracts on several parameters used as a measure against toluene toxicity. The aqueous extract of $P$. peruviana was reported to comprise of phenol and saponin flavonoids as the major constituents by a 
phytochemical study. These compounds possessed antioxidant activity (Ramadan and Moersel, 2003). Another study also reported $P$. peruviana to possess antioxidant activity (Wu et al., 2005).

Arvindkumar et al. (2011) performed nephrectomy on male Wistar rats with the aim of determining the protective role of LU (flaxseed) ethanol extracts on rat kidneys. The experimental results indicated that the extract was effective on the protection of the kidneys elevating GSH and MDA concentrations, thereby reducing necrosis (Abdel-Moneim et al., 2011a). AbdelMoneim et al. (2011b) treated male rates with lead acetate, a toxic metal ion $(20 \mathrm{mg} / \mathrm{kg})$, and examined the effect of flaxseed oil (1000 mg/kg) at kidney cytotoxicity. The results of the study indicated that the rats that were given flaxseed oil along with lead acetate had similar GSH concentration and antioxidant enzyme levels as those of the control group. Furthermore, a considerable improvement was observed in the histopathology of the kidneys; i.e. its function and other factors including the antioxidant levels. This affirmative effect of flaxseed was reported to be associated with its lignan content (Arvindkumar et al., 2011).

The results of the experiments comparing the control group to that of the toluene treated group indicated that the MDA concentration was significantly elevated in group $\mathrm{T}$ whereas this level was limited in groups supplemented with the extract. The decrease in GSH concentration was noticeable in group T. The GSH concentration to the control group with to the extract-supplemented groups was statistically similar. The present findings are consistent with previously reported studies (Table 1). Many of those botanical-based studies supporting as a results of this study reported protective features of phytochemicals against oxidative stress occurring in the liver and kidney tissue, which was at the tissue under investigation in the present analysis as well. Moreover, another study presents the impact of ROS on the antioxidant defense mechanisms by reducing glutathione concentration in the intracellular (Tapiero et al., 2002).

Another study reported a variety of levels of lipid peroxidation with endogenous antioxidant levels to workers who were exposed to paint (Meek and Chan, 1994). Intraperitoneal injection of toluene results in a similar damage to the body of inhalation. This study indicated that GSH concentration with the protein content of the toluene-treated groups was importantly lower than the control group (Tables 1, 2). The GSH level of control group and that of the $P$. peruviana-treated group were statistically similar (Tables 1, 2). This affirmative effect of $P$. peruviana was thought to be caused by the phytochemicals and phenolic compounds in its composition (Tables 3, 4). In this context, 28hydroxywithanolide, withanolides, phygrine, kaempferol, and quercetin diandtriglycosides in Physalis spp are investigated (Abdel Moneim, 2016; AbdelMoneim et al., 2014; Fang et al., 2012; Arun and Asha, 2007).

The vitamin and cholesterol compositions were various owing to the phytochemical content of the plant extracts. In this study, the analyzes were done on HPLC equipment showed that in methanol extract of PP with $\mathrm{LU}$, there were $\alpha$-tocopherol, $\delta$-tocopherol, 
vitamins $\mathrm{D}_{3}, \mathrm{E}$ with $\mathrm{K}$, stigmasterol, $\beta$ sitosterol, retinol molecules with flavonoids (e.g. cathechin, rutin, myricetin, morin with naringenin) (Tables 3, 4). Vitamin concentration in groups supplemented with PP and LU being similar to those in the control group and this value being higher than the one measured for group $\mathrm{T}$ would indicate that this fruit would have a rich vitamin and mineral content (Tables 5, 6).

Plant sterols are compounds that have similar chemical structures and function in a similar way with cholesterol. Stigmasterol is the most common plant sterol. In contemporary diet, the daily uptake of plant sterols is estimated to be in the range of 160-400 mg whereas this number was thought to reach or exceed one gram in ancient cultures. Nuts, cereals and seeds are good sources of plant sterols. $\beta$-sitosterol, campesterol and stigmasterol are the most common varieties of sterols found to the plants. The absorption of plant sterols in humans is less than that of cholesterol. The cholesterol absorption inhibition characteristic of plants sterols was investigated primarily due to the structural similarities between plant sterols and cholesterol (Scalzo et al., 2005).The high polyunsaturated fatty acid content and the presence of some fatty acid compounds make P. peruviana, which was used in this study, an ideal nutrient (Ramadan and Moersel, 2003). The investigation of the vitamin concentrations to this study indicated that to concentrations of some vitamins were considerably higher in the extract supplemented LU and PP groups by comparison that of the group $\mathrm{T}$ (Tables 5, 6). Furthermore, the concentration of many vitamins in groups $\mathrm{T}+\mathrm{LU}$ and $\mathrm{T}+\mathrm{PP}$ was very similar to their values in the control group, and some were reported to be higher than those measured in the tissue samples of the control group. The results of the presently conducted experiments indicate that the cholesterol concentration was higher in group $\mathrm{T}$, which was exposed to toxic materials. Cholesterol concentration in groups $\mathrm{T}+\mathrm{LU}$ and $\mathrm{T}+\mathrm{PP}$, which were supplemented with extracts, was lower and similar to the value of the control group (Tables 5, 6).

The results of the fatty acid analysis indicated an elevation in the concentration of some fatty acids and the phyto extract in $\mathrm{T}+\mathrm{LU}$ and $\mathrm{T}+\mathrm{PP}$ groups compared to the values measured for group $\mathrm{T}$ samples. This situation might have stemmed from the supplemented chemicals and plant extracts affecting the fatty acid metabolism. The C16:0 concentration in the kidney tissue of group $\mathrm{T}$ rats was significantly less than that of the control group (Table 7). This situation might have been caused by chemicals for example toluene, affecting the activity of enzymes such as acetyl-CoA carboxylase and fatty acid synthase that play a role in lipid biosynthesis since C16:0 is the final step in fatty acid biosynthesis; it is synthesized by fatty acid synthase and released through a series of enzymatic reactions. Therefore, a decrease in the C16:0 concentrations might be explained by a decrease in fatty acid synthesis. On the other hand, the C16:1 concentration in group $\mathrm{T}$ was considerably lower than the control group (Table 7). This decrease was assumed to have been caused by the inhibition of SCD activity. The C18:2n-6c (linoleic acid) concentration in the kidney and liver tissues of the toluene treated rats was much lower than the control group's value. The decrease in C18:2n-6c concentration would be an indicator of a decrease in the activity to the 
delta 6 and delta 5 desaturase enzymes that belong to the delta 6 desaturation metabolic pathway. This would possibly be the reason for the change in the linoleic acid concentration in the tissue (Table 8).

Toluene results in a severe environmental pollution since it is commonly preferred by the industrial organizations. The impacts of toluene on animals and human were examined by various studies. The experimental studies show that antioxidants have constructive abilities against toluene's destructive effects. In this work, investigation of the antioxidant effects for PP and LU was performed through the animal experiments by inducing oxidative stress with toluene. The plant extracts used in the present study were proved to be effective in the prevention of LPO in vivo. The fatty acid and vitamin profiles and GSH with total protein concentrations were determined in Sprague Dawley rats. The results show that oxidative stress induced by toluen is eliminated with PP and LU compounds. We hope the results of this study will shed light on further studies focusing on the utilization of natural plant antioxidants against several xenobiotics which we are frequently exposed to.

\section{Acknowledgements}

This work was supported by the Firat University Research Fund (FÜBAP Project number FF.12.11). The experimental study was provided by the Experimental Research Center at Firat University School of Medicine (22.05.2012/66). This study is a part of the first author's PhD thesis. A part of this study declared poster in 23 National Biology Congress.

\section{Conflicts of Interest}

The author declares no conflict of interest.

\section{Author Contribution Statements}

Zehra GÖKÇE and Ökkeş YILMAZ conceived and designed the experiments. Zehra GÖKÇE performed the experiments. Ökkeş YILMAZ supervised the research activity and setup methodology of experiment. Zehra GÖKÇE wrote the paper and Hatayi ZENGIN contributed to writing the paper.

\section{References}

1. Abdel Moneim A.E., Prevention of carbon tetrachloride $(\mathrm{CCl} 4)$ induced toxicity in testes of rats treated with Physalis peruviana $\mathrm{L}$. fruit,.Toxicology and Industrial Health., 32-6 (2016) 1064-1073.

2. Abdel-Moneim A.E., Bauomy A.A., Diab M.M., Shata M.T., Al-Olayan E.M. and El-Khadragy M.F.,The Protective Effect of Physalis peruviana L. Against Cadmium-Induced Neurotoxicity in Rats,Biological Trace Element Research.,160-3 (2014) 392-399.

3. Abdel-Moneim A.E., Dkhil M.A. and Al-Quraishy S., The protective effect of flaxseed oil on lead acetateinduced renal toxicity in rats, Journal of Hazardous Materials., 194-1 (2011a) 250-255.

4. Abdel-Moneim A.E., Dkhil M.A. and Al-Quraishy S., The redox status in rats treated with flaxseed oil and lead-induced hepatotoxicity, Biological Trace Element Research143-1 (2011b) 457-467.

5. Abdel-Salam, O.M., Sleem, A. A., Khadrawy, Y.A., and Morsy, F.A. Prevention of toluene- induced brain neurodegeneration by atropine and neostigmine. Journal of Basic Pharmacology and Toxicology, 4(1), (2020).1-9.

6. Arun M. and Asha V.V., Preliminary studies on antihepatotoxic effect of Physalis peruviana Linn.against carbon tetrachloride induced acute liver injury in rats, The Journal of Ethnopharmacology 111-1 (2007) 110-114.

7. Arvindkumar E.G., Suresh S. and Jadhav S.L., Renoprotective effect of Linum usitatissimum seeds through haemodynamic changes and conservation of antioxidant enzymes in renal ischaemia reperfusion injury in rats, Arab Journal of Urology, 9-3 (2011) 215-221.

8. Aylward L.L., Barton H.A. and Hays S.M., Biomonitoring equivalents (BE) dossier for toluene (CAS No. 108 88-3), Regulatory Toxicology and Pharmacology., 51-3 (2008) 2736.

9. Bayil S., Cicek H., Cimenci I.G. and Hazar M., How volatile organic compounds affect free radical and antioxidant enzyme activity in textile workers, Journal of industrial hygiene and toxicology., 59-4 (2008) 283-287. 
10. Christie W.W., Gas chromatography and lipids, The Oil Pres, Glaskow (1990).

11. Costa C., Pasquale R., Silvari V., Barbaro M. and Catania S., In vitro evaluation of oxidative damage from organic solvent vapors on human skin, Toxicology in Vitro ., 20-3 (2005) 324-331.

12.EPA., USA., Toxicological Review of Toluene, EPA/635/R-05/004 (1959).

13. Fang S.T., Liu J.K. and Li B., Ten new withanolides from Physalis peruviana, Steroids., 77-1 (2012) 36-44.

14.Gerin M., Siemiatychi J., Desy M. and Krewski D., Associations between several sites of cancer and occupational exposure to benzene, toluene, xylene, and styrene: results of a case-control study in Montreal,American Journal of Industrial Medicine., 34-2 (1998) 144-156.

15.Gholaminejhad M., Arabzadeh S., Akbari M., Mohamadi Y. and Hassanzadeh G., Anti-oxidative and neuroprotective effects of flaxseed on experimental unilateral spinal cord injury in rat. Journal of Contemporary Medicine 3-10 (2017) 213-217.

16.Gotohda T., Nishimura A. and Morita K., Immuno histochemical studies on early stage of hepatic damage induced by subacute inhalation of toluene vapor in rats, Journal of Applied Toxicology, 29-6 (2009) 505-509.

17. Hara A. and Radin N.S., Lipid extraction of tissues with a low-toxicity solvent, Journal of Biochemistry and Analytical Biochemistry., 90-1 (1978) 420-426.

18. Hendawi M.Y., Alam R.T. and Abdellatief S.A., Ameliorative effect of flaxseed oil against thiacloprid-induced toxicity in rats: hematological, biochemical, and histopathological study, Environmental Science And Pollution Research International., 23-12 (2016) 11855-11863.

19. Huff J., Absence of carcinogenic activity in Fischer rats and B6C3F1 mice following 103-week inhalation exposures to toluene, International Journal of Occupational Safety and Health., 9-2 (2003) 138- 146.

20.Jamshidi-Kia F., Lorigooini Z. and Amini-Khoei H. . Medicinal plants: past history and future perspective, Journal of Herbmed Pharmacology 7(1) (2018) 1-7.

21. Katsanidis E. and Addis P.B., Novel HPLC analysis of tocopherols and cholesterol in tissue, Free Radical Biology and Medicine., 27 - 1 (11-12) (1999) 1137-1140.

22. Kaur N., Kishore L. and Singh R., Therapeutic effect of Linum usitatissimum L. in STZ-nicotinamide induced diabetic nephropathy via inhibition of AGE's and oxidative stress. The Journal of Food Science and Technology., 54-2 (2017) 408-421.

23. Kayhan F.E.B., Koç N.D., Contuk G., Muşlu M.N. and Sesal N.C., Sıçan Böbrek Dokusunda Endosulfan ve
Malathion'un Oluşturduğu Yapısal Değișiklikler, Journal of Science and Arts J., 12-1 (2009) 43-51.

24. Khalaf-Allah A.E.R.M., El-Gengaihi S.E., Hamed M.A., Zahran H.G. and Mohammed M.A., Chemical composition of goldenberry leaves against hepatorenal fibrosis. Journal of dietary supplements., 134 (2016) 378-392.

25. Kris-Etherton P.M., Lefevre M., Beecher G.R., Gross M.D., Keen C.L. and Etherton T.D., Bioactivecompounds in nutrition and healthresearch methodologies for establishing biological funtion: the antioxidant and anti-inflammatory effects of flavonoids on atherosclerosis, The Annual Review of Nutrition., 24-1 (2004) 511-538.

26. Lowry O.H., Rosenbrough N.J., Farr A.L. and Randall R.J., Protein measurement with the folinphenolreagent, Turkish Journal of Biochemistry., 193-1 (1951) 265-277.

27. Meek M. and Chan P., Toluene: evaluation of risks to human health from environmental exposure in Canada, Environmental Carcinogenesis and Ecotoxicology Reviews., 12-1 (1994) 507-515.

28. Moro A.M., Charao M., Brucker N., Bulcao R., Freitas F., Guerreiro G., Baierle M., Nascimento S., Waechter F., Hirakata V., Linden R., Thiesen F.V. and Garcia S.C., Evaluation of genotoxicity and oxidative damage in painters exposed to low levels of tolüene, Mutation Research., 746-1 (2012) 42- 48.

29. Moro A.M., Charão M., Brucker N., Bulcão R., Freitas F., Guerreiro G., Baierle M., Nascimento S., Waechter F., Hirakata V., Linden R., Thiesen F.V. and Garcia S.C., Effects of low-level exposure to xenobiotics present in paints on oxidative stress in workers., Science of the Total Environment., 408-20 (2010) 4461-4467.

30. Nasri H., World kidney day: acute kidney injury; a public health aware, Iranian Journal of Public Health., 42-1 (2013) 338-40.

31. Ohkawa H., Ohishi N. and Yagi K., Assay for lipid peroxides in animal tissues by thiobarbituric acid reaction, Analytical Biochemistry., 95-2 (1979) 351-358.

32. Parikh M., Maddaford T.G., Austri, J.A., Aliani M., Netticadan T. and Pierce G.N., Dietary Flaxseed as a Strategy for Improving Human Health. Nutrients., 11-5 (2019) 1171.

33. Ramadan M.F. and Moersel J., Oil goldenberry (Physalis peruviana L.), The Journal of Agricultural and Food Chemistry, 51-4 (2003) 969-974.

34.Scalzo J., Politi A., Pellegrini N., Mezzetti B. and Battino M., Plant genotype affects total antioxidant capacity and phenolic contents in fruit, Nutrition, 2-1 (2005) 207-213.

35. Tapiero H., Tew K.D., Ba G.N. and Mathe G., Do they play a role in the prevention of humanpathologies, Biomedicine and Pharmacotherapy, 56-4 (2002) 200-207. 
36.Teare, J.P., Punchard, N.A., Powell, J.J., Lumb, P.J., Mitchel, W.D. and Thompson, R.P.H. Automatedspectrophotometric method for determining oxidized and reduced glutathione in liver. Clinical Chemistry, 39-4 (1993) 686-689.

37.Trovato M. and Ballabio C., Botanical products: general aspects. In: Food supplements containing botanicals: benefits, side effects and regulatory aspects, Cham: Springer., (2018) 3-26.

38.Wu S.J., Ng L.T., Huang Y.M., Lin D.L., Wang S.S., Huang S.N. and Lin C.C. Antioxidant activities of Physalis peruviana, Biological and Pharmaceutical Bulletin., 28-6 (2005) 963-966.

39.Zu Y., Li C., Fu Y. and Zhao C., Simultaneous determination of catechin, rutin, quercetin kaempferol and isorhamnetin in the extract of sea buckthorn (Hippophae rhamnoides L.) leaves by RP-HPLC with DAD, Journal of pharmaceutical and biomedical analysis., 41-3 (2006) 714-719. 